\title{
Hugo et l'histoire, textes édités par Léon-François Hoffmann et Suzanne Nash
}

Judith Wulf

\section{(2) OpenEdition}

\section{Journals}

Édition électronique

URL : http://journals.openedition.org/studifrancesi/9287

DOI : 10.4000/studifrancesi.9287

ISSN : 2427-5856

Éditeur

Rosenberg \& Sellier

\section{Édition imprimée}

Date de publication : 1 juin 2008

Pagination : 209

ISSN : 0039-2944

\section{Référence électronique}

Judith Wulf, « Hugo et l'histoire, textes édités par Léon-François Hoffmann et Suzanne Nash », Studi

Francesi [En ligne], 154 (LII | I) | 2008, mis en ligne le 30 novembre 2015, consulté le 11 janvier 2021.

URL : http://journals.openedition.org/studifrancesi/9287; DOI : https://doi.org/10.4000/studifrancesi. 9287

Ce document a été généré automatiquement le 11 janvier 2021.

\section{(c) (†)}

Studi Francesi è distribuita con Licenza Creative Commons Attribuzione - Non commerciale - Non opere derivate 4.0 Internazionale. 


\section{Hugo et l'histoire, textes édités par Léon-François Hoffmann et Suzanne Nash}

Judith Wulf

\section{RÉFÉRENCE}

Hugo et l'histoire, textes édités par Léon-François HOFFMANN et Suzanne NASH, Fasano, Schena Editore / Presses de l'Université Paris-Sorbonne, 2005, pp. 244.

1 Pour son deuxième numéro, la collection «Trans-atlantique» publie les actes du colloque tenu à Princeton les 3 et 4 mai 2002, dans le cadre des manifestations du bicentenaire de la naissance de Victor Hugo. Les contributions reviennent sur la représentation hugolienne de l'histoire. Il s'agit de mettre en perspective l'originalité apportée par la fiction, qui envisage cette question de manière particulière: alors que le «discours public» apparaît comme «optimiste et progressiste», l'imaginaire historique de Hugo propose une «vision profondément ambiguë et même sombrement pessimiste». Portant sur la production écrite, mais également graphique, de Hugo, les diverses études mettent également l'accent sur le caractère "précurseur des innovations apportées au $\mathrm{xx}^{\mathrm{e}}$ siècle à la théorie critique, à la pensée politique et aux pratiques esthétiques». L'ouvrage est divisé en cinq sections centrées sur le cadre théorique, les années de jeunesse, Le Rhin, les rapports entre mots et images ainsi que l'idée de fin de l'histoire.

2 La première section, intitulée «Le cadre théorique: deux visions d'ensemble de la carrière de Victor Hugo» comprend les contributions de Guy RosA (Victor Hugo: Histoire vécue, histoire écrite, pp. 11-35) et Robert MORRISSEY (L'empereur, le poète et la mythistoire de Charlemagne, pp. 37-56). Le premier réfléchit sur l'influence que l'intrication entre vie, action et œuvres a eue sur la représentation de l'histoire chez Hugo. Le second s'intéresse à l'adhésion de Hugo à Napoléon, en montrant qu'elle est déterminée par un 
«mouvement qui remonte au dix-huitième siècle» et qui est «centré sur la figure de Charlemagne».

Dans la deuxième section, «Les années de jeunesse sous la Restauration», Pierre LAFORgue (Le Roi et le Moi. Politique et histoire chez Hugo, pp. 59-72) s'interroge sur la genèse de la textualisation du politique dans les années 1826-1829. Victor BROMBERT ("Le Dernier Jour d'un condamné": modèle récurrent du récit, pp. 73-83) s'intéresse à un texte qui «ne comporte d'histoire ni dans le sens collectif ni dans le sens personnel du mot» pour montrer que, très tôt dans l'œuvre de Hugo, la question est moins celle de la "progression historique» que celle «du drame et du progrès de la conscience humaine». Portant sur le même ouvrage, la contribution de David Bellos (Le Condamné de Hugo: Comme pour le roi, pp. 85-88) conclut à son statut de «modèle formel», ce qui lui confère une place particulière dans «l'histoire du roman et dans l'histoire tout court».

4 La troisième section, «1840 - Le Rhin: Un texte écartelé entre la Politique et l'Histoire», propose deux études sur ce texte. Marie-Catherine HUET-BRICHARD (L'écriture de l'Histoire dans "Le Rhin" ou le poète et Dieu, pp. 91-108) se penche sur les enjeux politique, poétique, philosophique et métaphysique qui constituent autant d'aspects de la réflexion sur l'histoire, tandis que Suzanne GUERLAC (pp. 109-134) consacre son étude à la "pratique visionnaire séculaire» de Hugo telle qu'elle se manifeste dans Le Rhin.

5 La quatrième section réunit «Les Mots et les Images: Hugo poète et dessinateur». Suzanne NASH (pp. 137-154, Couler Hugo dans l'histoire) procède à une étude de la statuaire hugolienne (David d'Angers et Rodin) et Pierre GEORGEL (pp. 155-215) analyse les «dessins de Victor Hugo autour de La Légende des siècles».

Dans la cinquième section, intitulée «La Fin de l'Histoire: Les Misérables», Kathryn M. GROSSMAN (pp. 219-228) examine les «variations cinématiques dans les dénouements hugolien» et Isabel K. ROCHE (pp. 229-241) «le personnage hugolien et son histoire dans Les Misérables». 